\title{
Formação continuada de professores: construindo possibilidades para o ensino do atletismo na Educação Física escolar ${ }^{*}$
}

\section{Continued formation of teachers: building possibilities for the teaching of athletics in school Physical Education}

\author{
Flórence Rosana Faganello Gemente** \\ Sara Quenzer Matthiesen***
}

\begin{abstract}
RESUMO
Esta pesquisa teve como objetivo oferecer um curso de formação continuada de professores, direcionado ao desenvolvimento do atletismo na Educação Física escolar, verificando suas contribuições para a prática pedagógica dos participantes. Para o desenvolvimento da pesquisa, realizamos um curso de formação continuada de professores com a participação de 21 professores de Educação Física da rede municipal de Educação de Goiânia. De natureza qualitativa, com elementos de pesquisa-ação, esta pesquisa utilizou diferentes técnicas para o levantamento de dados, tais como entrevistas, questionário, gravação e diário de campo. Os resultados revelaram que o curso de formação continuada proporcionou aos professores a troca de experiências; a construção de conhecimentos que contribuíram para a superação das dificuldades no trato das provas do atletismo abordadas no curso; a interferência direta na escola durante o processo de formação continuada; a elevação da autoes-
\end{abstract}

\section{DOI: $10.1590 / 0104-4060.49226$}

* Este texto é um desdobramento da tese de doutorado (FAGANELLO-GEMENTE, 2015) e de pesquisa financiada pela Fundação de Amparo à Pesquisa do Estado de Goiás (FAPEG) e Coordenação de Aperfeiçoamento de Pessoal de Nível Superior (Capes), através da Chamada Pública FAPEG n ${ }^{\circ}$ 08/2012 ACORDO CAPES/FAPEG.

** Universidade Federal de Goiás. Faculdade de Educação Física. Goiânia, Goiás, Brasil. Rodovia Goiânia-Nerópolis, km12. Jardim Pompéia. CEP: 74001-970. E-mail: florencefaganello@ gmail.com

*** Universidade Estadual Paulista Júlio de Mesquita Filho. Instituto de Biociências de Rio Claro. Rio Claro, São Paulo, Brasil. Av. 24A, n. 515. Bela Vista. Caixa-postal: 199. CEP: 13506900. E-mail: saraqm@rc.unesp.br 
tima dos professores; atendeu às necessidades dos professores; estimulou a criatividade para o desenvolvimento de novas práticas; e aproximou a universidade da escola. Com base nos resultados, reforçamos a importância da formação continuada para a construção de novos conhecimentos; ressaltamos a importância da aproximação entre a universidade e a escola, de modo a possibilitar a reflexão, discussão, construção e divulgação de novos conhecimentos relacionados ao atletismo para que os professores possam superar as dificuldades, desenvolvendo práticas pedagógicas que contemplem o atletismo de forma mais completa e aprofundada.

Palavras-chave: Atletismo. Educação Física escolar. Formação continuada.

\begin{abstract}
This research aimed to offer a course of continued formation of teachers, directed to the development of athletics in physical education in school, while checking its contributions to the pedagogical practice of the participants. For the development of the research, we carried out a course of continued formation for teachers, with the participation of 21 teachers of physical education of municipal schools of the state of Goiânia. With a qualitative nature, and action research elements, this research used different techniques to survey data, those being: interviews, questionnaires, recordings and field diaries. The results revealed that the course of continued formation provided an opportunity for teachers to exchange experiences; it also provided construction of knowledge that helped to overcome the difficulties in dealing with the athletic modalities approached in the course; it met the needs of the teachers; provided direct interference in school during the process of continued formation; stimulated creativity for the development of new practices; provided raising of the self-esteem of teachers and brought school and university together. Based on the results, we reinforce the importance of continued formation for the construction of new knowledge. We also emphasize the importance of bringing university and school together, in order to enable reflection, discussion, construction and dissemination of new knowledge related to athletics, so that teachers can overcome difficulties to develop pedagogical methods that address these practices in a deeper and more complete way.
\end{abstract}

Keywords: Athletics. Physical Education in school. Continued formation. 


\section{Contextualizando o atletismo na Educação Física escolar}

O atletismo sempre esteve presente na história da humanidade se considerarmos que suas diferentes provas exploram as diferentes habilidades motoras, as quais foram utilizadas para sobrevivência em épocas ancestrais. Na Grécia Antiga, suas provas se faziam presentes desde as primeiras edições olímpicas, sendo que, atualmente, é considerado como uma das modalidades esportivas mais tradicionais dos Jogos Olímpicos. Entretanto, ao mesmo tempo, o atletismo é pouco difundido no Brasil e praticamente esquecido nas aulas de Educação Física.

O estudo de Calvo (2005), por exemplo, revela a fragmentação do conhecimento sobre o atletismo dos acadêmicos dos cursos de Licenciatura e Bacharelado em Educação Física, cujo conhecimento, na maior parte das vezes, é pautado em conteúdos veiculados pela mídia, que espetaculariza o esporte, limita o atletismo a algumas provas, reforçando a superação de limites e de recordes. Tal entendimento do atletismo apenas como esporte de alto nível, que exige boa infraestrutura, materiais e espaços oficiais, bem diferentes da realidade escolar, contribui para que os professores de Educação Física se sintam impotentes para ensiná-lo na escola (MATTHIESEN, 2005). Outro fator que dificulta o entendimento do atletismo para além do esporte de alto nível são os trabalhos superficiais que acabam negligenciando parte de seu conteúdo, contemplando apenas as provas de corridas, as de saltos menos complexas, algumas vezes, as de arremesso de peso, sem que conheçam ou discutam sobre sua história, sua inserção na mídia, seu vínculo com as tecnologias, acarretando um conhecimento restrito acerca destas modalidades esportivas (MARQUES; IORA, 2009; CALVO; MATTHIESEN, 2012; PEDROSA et al., 2010; ARRUDA, 2012).

Assim as razões que levam os professores a não ensinar o atletismo nas aulas de Educação Física escolar estão relacionadas à falta de estrutura das escolas, falta de espaço e de materiais específicos, desinteresse dos alunos e da escola para com a Educação Física, falta de cultura e tradição dessa modalidade esportiva, como apresentam Arruda (2012), Silva, A. C. L. (2005), Matthiesen (2005, 2007), Lecina e Rocha Jr. (2001), Meurer, Schaefer e Miotti (2008). Além disso, a bibliografia da área está mais direcionada à formação de atletas e à realização de trabalhos em locais onde há uma pista e materiais oficiais, como apresentado por Faganello-Gemente e Matthiesen (2014). Tais dificuldades, relatadas pelos professores, podem estar direcionadas ao conhecimento restrito sobre o atletismo proveniente de sua própria formação e da falta de cursos de formação continuada, direcionados a essa modalidade esportiva, como foi constatado por Arruda (2012). 
Por outro lado, nota-se, em relação à formação inicial, que docentes de disciplinas de atletismo em diferentes universidades brasileiras têm tentado transformá-lo em algo mais acessível, demonstrando aos acadêmicos que para ensiná-lo não é necessário ter uma pista e materiais oficiais (SILVA; DARIDO, 2011). Porém, muitos professores que atuam nas escolas foram formados dentro de uma perspectiva que valoriza a técnica e a utilização de recursos oficiais (pista/implementos), encontrando dificuldades em trabalhar com o atletismo na Educação Física escolar, em superar a falta de infraestrutura das escolas, direcionando seu ensino à técnica e ao rendimento (ARRUDA, 2012).

Analisando a forma com que, tradicionalmente, o atletismo é trabalhado na escola, Kunz (2003, p. 130) considera ser impossível atribuir-lhe um valor "pedagógico-educacional", uma vez que "é pura busca de melhor rendimento", contribuindo para a exclusão de alunos, principalmente dos menos habilidosos. De acordo com Kunz (2003), as transformações precisam ocorrer em relação às limitações físicas e técnicas dos alunos para realizar determinados movimentos, enfatizando o prazer e a satisfação em se movimentar, uma vez que a tarefa da escola não é treinar o aluno, mas, estudar o esporte de forma atrativa, incluindo a efetiva participação de todos.

Diante desse contexto, consideramos necessária a realização de cursos de formação continuada direcionados ao trabalho com o atletismo no contexto escolar para que os professores possam superar as dificuldades em trabalhar com esse conteúdo em suas aulas. Nesse sentido, esta pesquisa teve como objetivo oferecer um curso de formação continuada de professores, fundamentado em suas dificuldades e necessidades em trabalhar com o atletismo na Educação Física escolar, verificando as possíveis contribuições para a sua prática pedagógica.

\section{Metodologia}

De natureza qualitativa, com elementos da pesquisa-ação, esta pesquisa utilizou diferentes técnicas para o levantamento dos dados, quais sejam: aplicação de questionários; realização de discussões durante os encontros de formação continuada; elaboração de diários de campo pelos professores participantes da pesquisa e pela pesquisadora; observação de algumas intervenções dos professores e entrevista semiestruturada, tendo sido aprovada pelo Comitê de Ética em Pesquisa da UFG (Protocolo $n^{0}$ 203/12) e, posteriormente, desenvolvida com o consentimento dos professores. 
De 2011 a 2013, a Faculdade de Educação Física (FEF) da Universidade Federal de Goiás (UFG), em Goiânia, e a Secretaria Municipal de Educação de Goiânia (SME) estabeleceram uma parceria que possibilitou a realização do Projeto de Extensão PRORROGAÇÃO, com o objetivo de proporcionar aos professores de Educação Física da rede municipal, a formação continuada no campo do esporte escolar. Com essa parceria, a FEF ficou responsável por cursos de 40 horas, com encontros quinzenais, e o Centro de Formação de Profissionais da Educação (CEFPE), da Secretaria Municipal de Educação, pela divulgação, permitindo aos professores a realização dos cursos em horário de estudo.

O curso de formação continuada de professores vinculado a essa pesquisa foi denominado como Pedagogia do Atletismo, contando com a participação de 21 professores de Educação Física da rede municipal de Educação de Goiânia, atuantes nos ciclos I, II e III e na EAJA, sendo 14 professoras e 7 professores. O curso ocorreu entre os meses de janeiro a junho de 2013, com encontros quinzenais, às terças-feiras no período matutino, em horário de estudo dos professores, totalizando 40 horas.

O objetivo do curso foi proporcionar aos professores o estudo, a reflexão e a discussão dos aspectos históricos, regulamentares e técnicos das provas do atletismo e a vivência de diferentes possibilidades de abordá-las no contexto escolar, propiciando a construção coletiva do conhecimento e a segurança dos professores para trabalhar com essa modalidade esportiva em suas aulas. Entendendo que um curso de 40 horas é insuficiente para tratar de todas as provas do atletismo, no primeiro encontro, a partir de suas dificuldades e interesses, os professores decidiram quais as provas do atletismo seriam estudadas no curso, tais como salto em altura, salto com vara, lançamento do dardo, lançamento do disco, lançamento do martelo e arremesso de peso. Vale lembrar que todas essas provas são do campo do atletismo.

A partir do segundo encontro, seguimos uma lógica de organização interna para os demais. Assim, ao iniciar os trabalhos sobre as provas do atletismo, realizamos, primeiramente, uma discussão sobre os conhecimentos dos professores acerca da prova. Nessas discussões, verificamos como trabalhavam com ela em suas aulas, quais as dificuldades encontradas e quais os aspectos que gostariam que fossem enfatizados. Em seguida, foram realizadas e vivenciadas diferentes propostas de atividades direcionadas aos aspectos históricos, regulamentares, técnicos e táticos das diferentes provas do atletismo. Ao final de cada encontro, uma roda de conversa era realizada para favorecer a reflexão sobre as atividades desenvolvidas e o levantamento de possibilidades e de adaptações para serem trabalhadas nas diferentes realidades dos professores, sendo que, durante esse processo de formação continuada, propusemos aos professores que realizassem, em suas aulas, intervenções relacionadas às provas do atletismo que estavam sendo abordadas no curso. 


\section{Conhecimentos e experiências dos professores relacionados ao atletismo}

No início do curso de formação continuada, buscamos conhecer como foi a formação dos professores em relação ao atletismo, suas vivências e experiências com essa modalidade esportiva, os trabalhos por eles realizados em suas aulas e as dificuldades relacionadas ao ensino do atletismo na escola.

No que se refere à formação, os professores relataram a falta de conhecimentos para trabalharem com o atletismo na Educação Física escolar, a falta de vivência na modalidade em outros contextos, uma vez que apenas três professores participantes foram atletas de provas de corridas do atletismo, além da repulsa à modalidade, decorrente de uma formação que exigia um bom desempenho técnico dos alunos. Em suas palavras:

É um esporte que no meu ver não foi bem trabalhado na minha formação inicial (P4).

Que a gente dentro da faculdade, dentro da academia, a gente tem toda uma estrutura completamente diferenciada, quando a gente vai pra escola a gente fica lá sem saber o que fazer (P6).

Eu acho que assim, deixou muito a desejar o meu conhecimento do atletismo dentro da minha formação (P16).

Eu vou ser honesta, eu tenho, eu tinha, verdadeiro pavor do atletismo. Eu fui muito mal preparada e a forma como fui avaliada era um sofrimento pra mim. Eu tinha verdadeiro ódio do atletismo. Eu passei a gostar e trabalhar depois que entrei na Prefeitura, que tem os Jogos Municipais. Então a partir dai eu fui obrigada a abrir meu coração mesmo, minha cabeça pra poder trabalhar com o atletismo (P17).

Pouco conhecimento na área e falta de espaço adequado para a realização das atividades (P21). 
Como podemos observar, o modo como o atletismo foi trabalhado na formação inicial, a falta de vivência na modalidade de forma mais lúdica e pedagógica ocasionou, a esses professores, dificuldades no desenvolvimento desse conteúdo em suas aulas. Além disso, podemos verificar que o direcionamento técnico, durante a formação da professora (P17), ocasionou o seu distanciamento do atletismo, dele se aproximando apenas devido aos Jogos Municipais. Tais dados reforçam os apontamentos de Arruda (2012) que, como vimos, ressalta que muitos professores que atuam há algum tempo nas escolas foram formados em uma perspectiva técnica que prioriza a utilização da pista e dos implementos oficiais.

Devido às lacunas da formação inicial, observamos que dos 21 professores participantes da pesquisa, uma afirmou que nunca trabalhou com o atletismo; mas, apenas, com as habilidades motoras de correr, saltar, lançar e arremessar, por considerar não possuir conhecimento e confiança suficientes para ensiná-lo em suas aulas. Nenhum professor afirmou ter trabalhado com todas as provas em suas aulas. Os vinte professores, que já trabalharam com o atletismo, relataram que abordaram apenas algumas delas, dada a facilidade de adaptá-las nas escolas, como é o caso das corridas. Como relatam:

A minha dificuldade com o atletismo e alguns outros esportes é a questão do demonstrar, então tem muita coisa que eu não sei fazer, eu tenho dificuldade. [...] eu tenho dificuldade em demonstrar, não sei fazer várias coisas [...]. Dardo eu não trabalho porque eu morro de medo dos meninos baterem o cabo de vassoura uns nos outros. Nada que possa, a possibilidade de desviar não faço, dardo eu não trabalho de jeito nenhum (P1).

[...] não esbarra só na quadra né? O espaço de guardar, porque as vezes a gente não tem sala pra guardar [...]. Como todo mundo, eu enfrento as mesmas dificuldades é, com relação a material. Então aqui a gente vai pelo que é mais fácil primeiro. Então, o ciclo I vai ficar com as corridas, já é mais tranquilo. Ainda assim, adaptar a ideia de pista ainda é um pouco complicado $(\mathrm{P} 4)$.

[...] para trabalhar o atletismo precisaria pelo menos de uma minipista, um espaço pra fazer os saltos, que seria a estrutura dos colchões, tatame e tal. Oferecer o menor risco possivel de se machucar, as escolas não têm. [...] tem algumas coisas que praticamente a gente elimina por conta desses riscos $(\mathrm{P} 6)$. 
As provas que eu tenho trabalhado são as corridas e os saltos. Ainda não trabalhei as provas de arremesso e lançamentos por falta de materiais adequados pra esta prática. Quando não é a falta de materiais me deparo com a falta de estrutura. Em alguns casos com a própria falta de formação em relação a algumas provas como salto em altura (P9).

Os relatos dos professores confirmam que a falta de estrutura física e de materiais são as principais dificuldades no trabalho com o atletismo nas aulas de Educação Física escolar, reforçando os apontamentos de Lecina e Rocha Jr. (2001), Silva, A. C. L. (2005), Matthiesen (2005, 2007), Meurer, Schaefer e Miotti (2008) e Arruda (2012). Devido às lacunas da formação inicial, os professores não se sentiam capazes de superar a falta de estrutura das escolas, não encontrando muitas possibilidades para a utilização e confecção de materiais que pudessem proporcionar a vivência e a construção de conhecimentos em torno do atletismo.

Diante dessas constatações, destacamos a necessidade de oferecer cursos de formação continuada a professores direcionados ao atletismo, uma vez que tanto os professores participantes desta pesquisa como os professores investigados por Arruda (2012), todos pertencentes à rede municipal de Goiânia, mencionam a falta de oferta de cursos de formação direcionado à área de Educação Física, de maneira geral, e ao atletismo, de maneira específica, fato que fica claro na fala do professor (P18):

A princípio me interessei pelo curso pois esta foi a primeira iniciativa de cursos destinados a professores de Educação Física da rede municipal. Há muito venho solicitando esse tipo de iniciativa (P18).

Diante desses dados, destacamos a importância de iniciativas nesse sentido, como é o caso do Projeto de Extensão PRORROGAÇÃO desenvolvido pela Faculdade de Educação Física da UFG/Goiânia, em parceria com a Secretaria Municipal de Educação de Goiânia - SME, que oferece cursos de formação continuada com diferentes conteúdos da Educação Física para os professores e do projeto de extensão desenvolvido pela Universidade Federal de Goiás Campus Catalão, que proporciona formação continuada para os professores da rede municipal (ARRUDA; OLIVEIRA; SILVA, 2011). Afinal entendemos que é a partir de cursos de formação continuada que os professores poderão superar 
as limitações da formação inicial e construir novos conhecimentos que contribuirão para o desenvolvimento de práticas pedagógicas direcionadas ao atletismo.

Em relação às vivências práticas, sempre no início do trabalho com determinada prova, os professores demonstravam-se pouco confiantes para sugerirem alguma atividade. Era preciso instigá-los a pensar sobre diferentes possibilidades de saltar, lançar e arremessar, fazendo uma aproximação com as provas do atletismo. Com o decorrer do curso, após a realização de algumas vivências, os professores apresentaram-se mais seguros para sugerir novas atividades ou adaptações àquelas já realizadas.

Quanto ao direcionamento do trabalho com o atletismo realizado pelos professores em suas aulas, é possível verificar a influência dos Jogos Escolares do município de Goiânia. Para acompanhar o calendário e a programação desses jogos, os professores procuram trabalhar o atletismo no primeiro trimestre de cada ano, abordando, nas aulas, as provas que correspondem àquelas disputadas pela faixa etária de seus alunos na competição. Além de programar o desenvolvimento dos conteúdos das aulas para acompanhamento do calendário dos jogos, percebe-se um direcionamento, por parte de alguns professores, para o desenvolvimento da técnica para a conquista de bons resultados e para a seleção dos melhores alunos para participarem dessa competição. Devido a esse direcionamento, os professores se mostraram preocupados com a possibilidade de transferência daquilo que foi vivenciado e aprendido por meio de jogos/ brincadeiras e com materiais alternativos, para o momento da competição, enfatizando, por exemplo:

Eu trabalho mais corrida, em vista aos Jogos. Eu seleciono eles de dois a dois pra, apostar corrida. Quem chega primeiro, eu vou tirando. Assim consigo levar os meninos bonzinhos pros Jogos (P5).

[...] até na nossa ficha de inscrição, na idade, só tem corrida e o salto em distância $(\mathrm{P} 6)$.

Lá na minha escola tem uma quadra, ai pro Jogos de atletismo eu faço vai e volta $(\mathrm{P} 7)$.

Eu sempre trabalho o atletismo nesse inicio justamente por causa dos Jogos. O primeiro é o atletismo, para não me pegar desprevenido. Você 
não ficar vendo lá que o aluno perdeu porque ele não prestou atenção ou ele não teve rendimento. Porque você espera que ele tenha um bom rendimento. É importante que eles saibam onde errou e o que aconteceu (P8).

Porque o atletismo faz parte do meu planejamento todo primeiro trimestre do ano. Por causa dos Jogos da prefeitura, eu participo já há 12 anos nesses jogos. Então o atletismo faz parte, mas eu dou uma ênfase maior nas competições de pista, porque nessa faixa etária do Ciclo II, não tem praticamente alunos que façam provas de campo, porque a prova de campo já é mais para o Ciclo III. Então como minha escola é Ciclo I e II eu dou ênfase maior nas corridas e os saltos. Lá a única prova de campo que eu trabalho mais o salto em distância, que é a prova que tem dentro do programa da prefeitura $(\mathrm{P} 10)$.

[...] é o segundo conteúdo que eu coloco por causa dos Jogos (P13).

Até onde, eu fico aqui imaginando [...] supõe-se que nós trabalhamos antes dos Jogos, que nos Jogos eles já tenham vivenciado aquilo. Mas quando chega lá [...] até onde, de fato, eles vão conseguir transferir as vivências para quando está com o sarrafo e colchão, já que na escola nunca teve colchão, nem sarrafo (P1).

Além da falta de estrutura das escolas e do conhecimento que acaba limitando o trabalho dos professores nas provas de corrida, é possível verificar por essas falas que os Jogos Escolares, por abordarem as mesmas provas todos os anos, acabam contribuindo para a fragmentação do conhecimento, ao invés de proporcionar a vivência em outras provas do atletismo e a construção de novos conhecimentos.

Devido ao formato competitivo dos Jogos Escolares, o direcionamento das aulas de Educação Física acaba ocasionando a exclusão dos alunos menos habilidosos, o que favorece o entendimento de que o atletismo é uma modalidade esportiva exclusivamente competitiva e que dificulta a atribuição de valores pedagógicos, como apontam Matthiesen (2005) e Kunz (2003) ao tratarem da forma como o atletismo é desenvolvido no ensino tradicional. Além disso, os professores podem estar enfatizando a dimensão procedimental, o "saber fazer", em detrimento das dimensões conceitual e atitudinal, resultado da herança histórica da Educação Física, como lembram Lazzarotti Filho e Figueiredo 
(2007), Darido et al. (2010) e Rodrigues e Darido (2011). Como consequência da ênfase no "saber fazer", os conhecimentos necessários para a formação do cidadão relacionados, por exemplo, ao processo histórico da modalidade, às questões sociopolíticas do atletismo, ao doping, à influência da mídia, à ética e ao lazer acabam sendo negligenciados nas aulas da Educação Física escolar.

Pela fala da professora (P1), podemos observar que, devido ao direcionamento das aulas visando aos Jogos Escolares, os professores apresentam dúvidas se as práticas pedagógicas que incluem os jogos, as brincadeiras e a utilização/ construção de materiais alternativos podem contribuir para a aprendizagem das habilidades que são exigidas nessa competição. Desse modo, entendemos que os Jogos Escolares podem estar dificultando o desenvolvimento de atividades pelos professores para além de uma perspectiva técnica. É importante destacar que o direcionamento do trabalho com o atletismo para os Jogos Escolares se aproxima dos dados encontrados por Frizzo (2012), os quais apontaram que os Jogos Escolares influenciam na seleção dos conteúdos da Educação Física e na metodologia das aulas, acarretando a centralização dos conteúdos nas modalidades esportivas e na priorização do treinamento em relação ao ensino dos conteúdos.

Com base nesses dados, avaliamos como necessário, durante os cursos de formação continuada, proporcionarmos aos professores o estudo, a reflexão e a discussão sobre o papel da Educação Física escolar como área de conhecimento e sua importância na formação do cidadão para que os Jogos Escolares possam influenciar cada vez menos as escolhas dos conteúdos e das práticas pedagógicas realizadas nessas aulas.

\section{Superando as dificuldades}

A infraestrutura das escolas é uma das dificuldades apresentadas pelos professores no trabalho com o atletismo nas aulas de Educação Física escolar devido à falta de materiais e espaço físico, corroborando com os dados presentes na literatura (ARRUDA, 2012; SILVA, A. C. L., 2005; MATTHIESEN, 2005, 2007; LECINA; ROCHA JR., 2001; MEURER; SCHAEFER; MIOTTI, 2008). Assim, durante o curso "Pedagogia do Atletismo", buscamos apresentar diferentes possibilidades de trabalhar com o atletismo nos locais disponíveis nas escolas, como a quadra esportiva/pátios, utilizando-se dos materiais alternativos.

Durante as intervenções, todos os professores confeccionaram e/ou utilizaram materiais alternativos para a realização de suas propostas pedagógicas 
e, de acordo com eles, contribuíram para suprir as necessidades das escolas e favoreceram à motivação e à aprendizagem dos alunos, como relatam:

Eu achei excelente, muito bom, muito motivante pra eles e pra gente também, principalmente na hora de confeccionar o material. Depois eles ficam perguntando quando iriam arremessar (P5).

A construção dos próprios materiais que foi o principal pela falta que a escola tem de material. [...] o que a gente aprendeu aqui de confeccionar material foi um sucesso, tanto que eles fazem brincando agora. E você vê que o peso está lá na hora do recreio (P8).

Eles adoraram, principalmente o fato deles estarem montando e construindo a bola. Uns queriam usar a bola antes mesmo de terminar, antes de passar a fita eles já queriam usar (P7).

É viável sim a prática do atletismo dentro da escola, é possivel, apesar da gente pensar que precisa do sarrafo, precisa do colchão. Mas é possivel sim trabalhar por meio de materiais alternativos (P9).

Além dos relatos dos professores que evidenciam o êxito do trabalho com materiais alternativos, em uma de nossas observações da aula do professor (P8), foi possível verificar a grande participação e envolvimento dos alunos na construção do peso. Após a construção do material, os alunos externavam satisfação de tê-lo construído e a vontade de experimentá-lo já naquela aula. Porém, essa atividade estava programada para outro dia.

Esses dados reforçam os apontamentos sobre as possibilidades e as contribuições da construção de materiais e do uso de materiais alternativos para o processo de ensino e aprendizagem do atletismo na escola, mencionado por autores como Maciel e Dollo (2004), Limão et al. (2004), Matthiesen (2005), Mezzaroba et al. (2006), Justino e Rodrigues (2007) Marques e Iora (2009), reforçando a necessidade de oferecer aos acadêmicos e aos professores de Educação Física uma formação que vá além das questões técnicas da modalidade e que trabalhe as diferentes dimensões dos conteúdos, considerando as questões materiais e estruturais das escolas brasileiras. Além disso, entendemos que 
proporcionar aos alunos a experiência de construir novos materiais a partir de recursos disponíveis, incentiva a criatividade e colabora para a autonomia dos alunos para que realizem novas vivências em outros ambientes além da escola.

Com a possibilidade de colocar em prática os estudos e as vivências realizados durante o curso de formação continuada, os professores puderam avaliar, refletir e dialogar sobre as suas práticas e contribuições do curso. Diferente das dificuldades, das limitações e dos receios em trabalhar com todas as provas do atletismo que foram apresentados pelos professores no início da pesquisa, foi possível verificar diversas contribuições do processo desenvolvido, tais como: a construção de novos conhecimentos que contribuíram para superar lacunas deixadas na formação inicial, o que possibilitou trabalhar com as provas do atletismo, em todos os ciclos de aprendizagem, que nunca haviam sido trabalhados; as vivências e as discussões realizadas estimularam a criatividade para o desenvolvimento de novas práticas e proporcionaram a elevação da autoestima dos professores. Como relatam:

Participando desse processo aumentou a minha criatividade na hora de elaborar as aulas [...] (P2).

O curso contribuiu muita em minha prática, no sentido de que abriu possibilidades de trabalhar com provas do atletismo que eu não imaginava serem possiveis sem o material e aparelhos adequados. Também tive acesso às regras, técnicas, dinâmicas e metodologias que não vivenciei em minha formação inicial e que abriram possibilidades de trabalho em todos os ciclos (P4).

Hoje eu não tenho mais dificuldades em trabalhar com o atletismo nas aulas (P5).

[...] trabalhar o salto com vara, o lançamento do dardo, o lançamento do martelo, tudo isso pra mim era assim, uma coisa impossivel dentro da escola. Na verdade, o que eu posso falar que era impossivel, mas que agora já é possivel trabalhar todos esses. [...] esse conhecimento foi adquirido agora, através do curso. [...] eu me sinto realizado, porque minha autoestima tá bastante elevada justamente por ter esse acesso, a esse conteúdo $(\mathrm{P} 8)$. 
Nunca tinha conseguido passar pra além das corridas [...]. Mas, aqui no curso, a gente teve uma possibilidade muito bacana de ver, de abrir os olhos para essas outras práticas [...] (P9).

Essas afirmações retratam a satisfação dos professores com os novos conhecimentos construídos durante o processo, o que, de acordo com I. S. Silva (2005), contribuiu para que dessem continuidade às práticas pedagógicas direcionadas ao atletismo mesmo com o término da pesquisa. Diferente do conhecimento fragmentado, decorrente do trabalho com apenas algumas provas do atletismo, os professores passaram a demonstrar a necessidade e as possibilidades de organizar pedagogicamente o conteúdo do atletismo no decorrer dos anos dos ciclos de aprendizagem, como podemos observar nos relatos:

Por isso que eu falo que daqui 5 anos, eu creio que todo o conteúdo do atletismo estará organizado. Todas as atividades com um grau de desenvolvimento, que eu acho que é melhor pra escola (P8).

Dentro de uns três anos que nós temos, a organização pedagógica desse conteúdo, dentro dos três anos tem que ser [...]. É uma coisa gradual (P9).

[...] eu tive uma vitória boa lá, porque eu consegui incluir o atletismo no $7^{\circ}$ ano também. Convenci a minha coordenadora de que trabalhar o atletismo um bimestre só no $6^{\circ}$ ano é pouco. Então agora nós fizemos uma divisão, nos $6^{\circ}$ e $7^{\circ}$ anos a gente vai trabalhar atletismo (P10).

Esses dados reforçam a importância da formação continuada para a construção de novos conhecimentos e da necessidade de elaboração de novas práticas que sejam significativas para a aprendizagem dos alunos. Assim o conteúdo do atletismo poderá ser organizado no decorrer dos anos escolares, proporcionando a eles um conhecimento completo e aprofundado sobre essa modalidade esportiva. Além disso, os relatos dos professores corroboram com as afirmações de Mendes (2008) sobre a importância de propiciar aos professores uma formação que possibilite colocar em prática o que está sendo estudado, pois contribui para a construção coletiva do conhecimento e para a práxis pedagógica.

Em relação à oferta e à participação dos professores no curso de "Pedagogia do Atletismo", entendemos ser necessária a oferta do curso no horário 
de trabalho dos professores. Nesse sentido, destacamos que a parceria com o CEFPE foi fundamental para que isso ocorresse, garantindo a presença dos professores. Aliás, essa possibilidade de realizar o curso no horário de trabalho foi bem elogiada pelos professores, uma vez que devido à excessiva carga horária de trabalho não conseguiriam realizar a formação em outro período.

Além disso, ao final da pesquisa, os professores expressaram o desejo de dar continuidade à formação ou de organizarmos um grupo de estudos para que pudessem aprofundar os conhecimentos e estudar novas possibilidades para trabalhar com o atletismo. Tais dados reforçam as afirmações de Paiva (2013) sobre a importância da formação permanente para que os professores possam estar sempre atualizando e compartilhando seus conhecimentos e experiências, esclarecendo dúvidas, superando dificuldades, elaborando novas práticas, que possam ser discutidas coletivamente.

\section{Considerações finais}

A partir da aproximação com os professores da rede municipal de Goiânia, constatamos que a falta de formação e/ou de uma formação direcionada a uma perspectiva técnica não ofereceu subsídios para o trabalho com o atletismo na escola, ocasionando o distanciamento de alguns professores dessa modalidade esportiva. Com isso, o conteúdo do atletismo desenvolvido nas escolas estava restrito às corridas, às atividades que enfatizavam a dimensão procedimental, acarretando o direcionamento do trabalho, de alguns professores, para os Jogos Escolares.

A formação continuada, que propusemos aos professores, uniu estudos, reflexões, discussões e vivências, o que contribuiu para a construção de novos conhecimentos relacionados ao atletismo. Os professores passaram a reconhecer a necessidade de realização de novas práticas, vivenciaram a possibilidade de desenvolver as provas de campo do atletismo nos espaços disponíveis das escolas e constataram o interesse dos alunos para trabalharem com o atletismo, construindo e utilizando materiais alternativos, iniciando, com isso, um caminho rumo à transformação do trabalho docente em relação ao ensino do atletismo em aulas de Educação Física escolar.

Avaliamos que, embora as condições de infraestrutura das escolas dificultem o desenvolvimento de novas práticas pedagógicas, a principal dificuldade dos professores em trabalhar com o atletismo é a formação. Assim destacamos a necessidade de propostas direcionadas à formação continuada dos professores 
e a importância de aproximar a universidade e a escola, de modo a favorecer a construção de novos conhecimentos que possam superar as dificuldades encontradas no cotidiano escolar, contribuindo para o desenvolvimento de práticas pedagógicas que contemplem o atletismo e os demais temas da cultura corporal de forma mais completa e aprofundada.

\section{REFERÊNCIAS}

ARRUDA, G. S. Atletismo nas aulas de Educação Física escolar na rede municipal de Goiânia. 2012. 54 f. Trabalho de Conclusão de Curso (Educação Física) - Universidade Federal de Goiás, Goiânia. 2012.

ARRUDA, L. C.; OLIVEIRA, A. P.; SILVA, A. P. P. Oficinas pedagógicas e metodológicas de atletismo: possibilidades de formação e aprendizagem nas escolas públicas de Catalão/GO. In: VI CONVERSAS COM QUEM GOSTA DE ATLETISMO. Goiás. Anais... Instituto de Biociências de Rio Claro - UNESP, 2011.

CALVO, A. P. O. O Atletismo como conteúdo da educação física escolar: estudo realizado com universitários da UNESP - Rio Claro. 2005. 51 f. Trabalho de Conclusão de Curso (Graduação em Licenciatura em Educação Física) - Instituto de Biociências, UNESP, Rio Claro. 2005.

CALVO, A. P.; MATTHIESEN, S. Q. Diagnóstico do conteúdo da Educação Física escolar: o atletismo em foco. Revista Digital Buenos Aires, Ano 16, n. 164, 2012. Disponível em: $<$ http://www.efdeportes.com/efd164/conteudo-da-educacao-fisica-escolar-o-atletismo.htm>. Acesso em: 11 fev. 2013.

DARIDO, S. C. et al. Livro didático na Educação Física escolar: considerações iniciais. Motriz, Rio Claro, v. 16, n. 2, p. 450-457, abr./jun. 2010.

FAGANELLO-GEMENTE, F.R. Atletismo na educação física escolar: a elaboração colaborativa do software atletic. 2015. 215 f. Tese (Doutorado em Desenvolvimento Humano e Tecnologias) - Instituto de Biociências, Universidade Estadual Paulista, Rio Claro (SP). 2015.

FAGANELLO-GEMENTE, F. R.; MATTHIESEN, S. Q. Análise dos livros de atletismo: subsídio para o ensino na Educação Física escolar. Revista Iberoamericana de Educación (Online), v. 65, p. 1-12, 2014. Disponível em: <http://www.rieoei.org/deloslectores/ 6246Faganello.pdf $>$. Acesso em: 17 jul. 2014.

FRIZZO, G. F. E. A organização do trabalho pedagógico da Educação Física na escola capitalista. 2012. $264 \mathrm{f}$. Tese (Doutorado em Ciências do Movimento Humano) - Escola de Educação Física, Universidade Federal do Rio Grande do Sul, Porto Alegre. 2012. Disponível em: <http://www.lume.ufrgs.br/handle/10183/60392>. Acesso em: 01 dez. 2014. 
JUSTINO, E. O.; RODRIGUES, W. Atletismo na escola: é possível? 2007. Disponível em: <http://educacaofisica.org/>. Acesso em: 12 jun. 2012.

KUNZ, E. Transformação didático-pedagógica do esporte. Ijuí: Unijuí, 2003.

LAZZAROTTI FILHO, A.; FIGUEIREDO, V. C. Editorial. Pensar a Prática. Faculdade de Educação Física, Universidade Federal de Goiás, v. 10, n. 2, jul./dez. 2007. Disponível em: <http://www.revistas.ufg.br/index.php/fef/article/view/1702/1678>. Acesso em: 15 out. 2011.

LECINA, L. A.; ROCHA JR., I. C. Diagnóstico do atletismo escolar em Santa Maria. Kinesis, Santa Maria, n. 25, 2001. Disponível em: $<$ http://cascavel.ufsm.br/revistas/ojs2.2.2/index.php/kinesis/article/view/10214>. Acesso em: 16 set. 2013.

LIMÃO, K.; LUÍZA, M.; GODOI, A. C.; ANJOS J. L.; TAVARES, O. A presença do atletismo em escolas do município de Vitória. In: ENCONTRO FLUMINENSE DE EDUCAÇÃO FÍSICA ESCOLAR, 7., 2004, Niterói. Anais... Niterói: Universidade Federal Fluminense, 2004, p. 91-93.

MACIEL, V.; DOLLO, A. S. E. O atletismo em aulas de educação física: novas formas de intervenção. In: ENCONTRO FLUMINENSE DE EDUCAÇÃO FÍSICA ESCOLAR, 7, 2004, Niterói. Anais... Niterói: Universidade Federal Fluminense, 2004, p. 249-251.

MARQUES, C. L. S.; IORA, J. A. Atletismo escolar: possibilidades e estratégias de objetivo, conteúdo e métodos em aulas de Educação Física. Movimento, Porto Alegre, v. 15, n. 2, p. 103-118, abr./jun. 2009.

MATTHIESEN, S. Q. (Org.). Atletismo se aprende na escola. Jundiaí: Fontoura, 2005.

MATTHIESEN, S. Q. Atletismo: teoria e prática. Rio de Janeiro: Guanabara Koogan, 2007.

MENDES, D. Luz, câmera e pesquisa-ação: a inserção da mídia-educação na formação continuada de professores de Educação Física. 2008. 201 f. Dissertação (Mestrado em Educação Física) - Centro de Desportos, Universidade Federal de Santa Catarina, Santa Catarina. 2008.

MEURER, S. T.; SCHAEFER, R. J.; MIOTTI, I. M. L. Atletismo na escola: uma possibilidade de ensino. Revista Digital, Buenos Aires, Año 13, n. 120, mayo 2008. Disponível em: $<$ http://www.efdeportes.com/efd120/atletismo-na-escola.htm/>. Acesso em: 16 set. 2013.

MEZZAROBA C.; ROMANSINI L. A.; MOREIRA E. L.; PEREIRA H.; SOUZA E. R. A visão dos acadêmicos de Educação Física quanto ao ensino do atletismo na escola. Lecturas, Educación Física y Deportes: Revista Digital, Buenos Aires, Año 10, n. 93, feb. 2006. Disponível em: <http://www.efdeportes.com/efd93/atlet.htm>. Acesso em 30 ago. 2006.

PAIVA, V. L. M. A. O. A formação do professor para uso da tecnologia. In: SILVA et al. (Org.). A formação de professores de línguas: novos olhares. v. 2. Campinas: Pontes 
Editores, 2013. p. 209-230. Disponível em: <http://www.veramenezes.com/formtec. pdf>. Acesso em: 21 nov. 2013.

PEDROSA, O. P. et al. A prática de atletismo nas aulas de Educação Física nas escolas de ensino fundamental no município de Porto velho. In: SEMANA EDUCA. Anais..., v.1, n.1, não p., 2010. Disponível em: <http://www.periodicos.unir.br/index.php/semanaeduca/article/view/108/148>. Acesso em: 9 jun. 2013.

RODRIGUES, H. A.; DARIDO, S. C. O livro didático na Educação Física escolar: a visão dos professores. Motriz, Rio Claro, v. 17, n. 1, p. 48-62, jan./mar. 2011. Disponível em: <http://www.scielo.br/pdf/motriz/v17n1/a07v17n1.pdf>. Acesso em: 05 maio 2014.

SILVA, A. C. L. O atletismo em aulas de Educação Física: pesquisa com professores da rede pública de Rio Claro. 2005. 66 f. Monografia (Trabalho de Conclusão de Curso em Educação Física) - Instituto de Biociências, Universidade Estadual Paulista, Rio Claro. 2005.

SILVA, E. V. M.; DARIDO, S. C. O atletismo nos cursos de graduação em Educação Física. Motriz, Rio Claro, v. 17, n. 3, p. 525-532, jul./set. 2011. Disponível em: $<$ http:// www.scielo.br/pdf/motriz/v17n3/15.pdf>. Acesso em: 10 maio 2014.

SILVA, I. S. Perfil do atletismo nas escolas públicas do ensino fundamental de Porto Velho. 2005. 48 f. Monografia (Licenciatura em Educação Física) - Núcleo de Saúde da Universidade Federal de Rondônia, Porto Velho. 2005. Disponível em: <http://www. def.unir.br/downloads/1202_perfil_do_atletismo_nas_escolas_publicas_do_ensino_fundament.pdf>. Acesso em: 20 nov. 2013.

Texto recebido em 10 de novembro de 2016. Texto aprovado em 09 de fevereiro de 2017. 